\title{
Wing profile evolution driven by computational fluid dynamics
} $\overline{\text { Evolución de perfil alar conducida por dinámica de fluidos }}$
computacional

\author{
Cristian C. Rendon ${ }^{1 a}$, José L. Hernandez ${ }^{\text {1b }}$, Oscar Ruiz - Salguero ${ }^{1 \mathrm{c}}$, Carlos A. Alvarez ${ }^{2}$, Mauricio Toro ${ }^{3}$ \\ ${ }^{1}$ Laboratory of CAD CAM CAE, Universidad EAFIT, Colombia. \\ Email: acrendo11@eafit.edu.co, b jlhernande@eafit.edu.co, ${ }^{c}$ oruiz@eafit.edu.co \\ ${ }^{2}$ Fluid Dynamics Laboratory, Universidad EAFIT, Colombia. Orcid: 0000-0003-0463-330X. \\ Email: calvar52@eafit.edu.co \\ ${ }^{5}$ GIDITIC Research Group, Universidad EAFIT, Colombia. Orcid: 0000-0002-7280-8231. \\ Email: mtorobe@eafit.edu.co
}

Received: 23 May 2018. Accepted: 11 November 2018. Final version: 28 January 2019.

\begin{abstract}
In the domain of fluid dynamics, the problem of shape optimization is relevant because is essential to increase lift and reduce drag forces on a body immersed in a fluid. The current state of the art in this aspect consists of two variants: (1) evolution from an initial guess, using optimization to achieve a very specific effect, (2) creation and genetic breeding of random individuals. These approaches achieve optimal shapes and evidence of response under parameter variation. Their disadvantages are the need of an approximated solution and / or the trial - and - error generation of individuals. In response to this situation, this manuscript presents a method which uses Fluid Mechanics indicators (e.g. streamline curvature, pressure difference, zero velocity neighborhoods) to directly drive the evolution of the individual (in this case a wing profile). This pragmatic strategy mimics what an artisan (knowledgeable in a specific technical domain) effects to improve the shape. Our approach is not general, and it is not fully automated. However, it shows to efficiently reach wing profiles with the desired performance. Our approach shows the advantage of application domain - specific rules to drive the optimization, in contrast with generic administration of the evolution.
\end{abstract}

Keywords: fluid mechanics; shape evolution; wing profile.

\section{Resumen}

En el dominio de mecánica de fluidos, el problema de optimización de forma es relevante porque es esencial incrementar la fuerza de elevación y reducir la de arrastre en un cuerpo inmerso en un fluido. El estado del arte actual consiste en dos variantes: (1) evolución a partir de una estimación inicial usando optimización para lograr un efecto específico, (2) creación y crianza genética de individuos aleatorios. Estos enfoques logran formas óptimas y evidencian la respuesta bajo la variación de parámetros. Sus desventajas son la necesidad de una solución aproximada y / o la generación de individuos por ensayo - y - error. En respuesta a esta situación, este manuscrito presenta un método que usa indicadores de Mecánica de Fluidos (e.g. curvatura en líneas de corriente, diferencia de presión, zonas de velocidad cero) para dirigir la evolución de un individuo (en este caso un perfil de ala). Se presenta una estrategia pragmática que imita las acciones de un artesano (conocedor de un dominio técnico en específico) para mejorar la forma. Nuestra aproximación no es general y no está completamente automatizada. Sin embargo, presenta eficiencia al alcanzar perfiles de alas con el desempeño deseado. Nuestra aproximación presenta la ventaja de tener un dominio y reglas de aplicación específicas para realizar la optimización, en contraste con la administración genérica de la evolución. 
Palabras clave: evolución de forma; perfil alar; mecánica de fluidos.

\section{Introduction}

In nature, constant perturbations of a fluid in objects make to change their shape in order to develop their dynamic behavior and evolve. Examples are eolic erosion or abrasion of rocks by streams. Similarly, engineering applies shape evolution techniques to develop devices or tools with optimal performance. Aeronautics focuses in the optimization of aerodynamic performance in aircraft with CFD.

Due to current computational power and mathematical models, this optimization can be partially conducted in silico, saving in costly wind tunnel and other experiments. The present work presents a methodology of experimentation with computational fluid dynamics (CFD) observing flow characteristics of an individual to evolve its shape achieving a required lift- and minimize drag- force.

\section{Literature Review}

The optimization process of a wing profile can be carried out in two ways, (1) evolution from an initial guess, using optimization, (2) creation and genetic breeding of random individuals.

Optimization methods use an objective function to be satisfied (e.g. gradient-based method [1, 2]). These methods are successful under one or two criteria to achieve a specific effect (e.g. lift production and / or drag reduction). The disadvantage is the need of an initial guess.
Ref. [3] determines Multivariable Polynomial Response Surfaces (MPRS) that express aero-dynamic performance measures (e.g. drag, lift) as functions of 2D control point sets. The point cloud of the MPRS is obtained by running Computational Fluid Dynamic simulations. After the MPRS are obtained, they are used to find the airfoil cross section control points which achieve the desired drag and / or lift. The 2D control points are constrained, in order to respect design conditions (e.g. space allowance for fuel compartment). The training of MPRS makes this method resemble Genetic Algorithms or Neural Networks. Ref. [4] describes a method to use multi-level constrains for the design of helicopter rotor blades. Since these blades suffer considerable challenge from conflicting design conditions, the constraints are organized in hierarchical manner. A genetic algorithm is used to administer the constraints, and dimensionality reduction (Principal Component Analysis) and Multi-Layer Hierarchical Constraint (MLC) methods are used to impose priorities on the design constraints. A large portion of the effort is devoted to find reduced representative constraint method out of a large hierarchical constraint set.

Ref. [5] discusses the optimization of the airfoil NACA 2411 by using genetic (PANEL) algorithms. The point set of the polygonal form of the airfoil is replaced by the PARSEC parameters for the purposes of lowering the size of the tuning variable set. The PARSEC parameterization is an airfoil - dedicated dictionary that translates fewer airfoil design parameters into full geometric profiles that are needed for the fluid dynamics simulation. This reference emphasizes the articulation of PANEL, PARSEC and Genetic Algorithms for the sake

Table 1. Different approaches and our contribution.

\begin{tabular}{|c|c|c|c|}
\hline Approach & Refs. & Advantages & Disadvantages \\
\hline $\begin{array}{l}\text { Evolution from an initial } \\
\text { guess, using optimization } \\
\text { methods }\end{array}$ & $\begin{array}{l}{[1,2,3,4} \\
5,6,7,8 \\
12, \\
17]\end{array}$ & $\begin{array}{l}\text { (1) Successful to achieve a } \\
\text { specific effect. }\end{array}$ & $\begin{array}{l}\text { (1) Initial guess } \\
\text { needed. }\end{array}$ \\
\hline $\begin{array}{l}\text { Creation and genetic breeding } \\
\text { of random individuals. }\end{array}$ & {$\left[\begin{array}{ll}{[8,10,} & 11, \\
13, & 14, \\
15] & \end{array}\right.$} & $\begin{array}{l}\text { (1) Evidence of response } \\
\text { under parameter variation. }\end{array}$ & $\begin{array}{l}\text { (1) Trial and error } \\
\text { methodology. }\end{array}$ \\
\hline $\begin{array}{l}\text { Our approach: To drive the } \\
\text { evolution of a random } \\
\text { individual using } \\
\text { Mechanics indicators }\end{array}$ & & $\begin{array}{l}\text { (1) The method presents an } \\
\text { evolution sequence. } \\
\text { (2) It is a pragmatic } \\
\text { methodology favoring the } \\
\text { understanding of the } \\
\text { phenomenon. }\end{array}$ & $\begin{array}{l}\text { (1) It is not fully } \\
\text { automated. }\end{array}$ \\
\hline
\end{tabular}

Source: the authors. 
of getting a coarse optimization, which effectively lowers the computational expenses. Ref. [6] presents an optimization of the landing for a morphing airfoil, conducted via iso-geometric analysis of potential flow. The iso-geometric analysis is a low - fidelity $2 \mathrm{D}$ one, that addresses both the fluid and the stress / strain of the profile (seen as Timoshenko beam). This reference makes emphasis on the direct usage of the beam B-Rep for the (i.e. iso-geometric) analysis of profile and fluid.

Ref. [7] focuses on the optimized design of super-critical wings. The manuscript uses 2D supercritical airfoil optimization (vis-a-vis pressure distribution). This optimization is the mapped to each cross section of the wing in the span direction via a so called $2.75 \mathrm{D}$ transformation. This transformation translates, back and forth, the pressure distribution between the wing and the $2 \mathrm{~d}$ cross sections (i.s. airfoils). The $2.75 \mathrm{D}$ transformation is a fitted function, that maps the wing parameters onto the pressure distribution along the wing. The method is a heuristic / empiric one, natural in an area in which the staggering computational and experimental expenses make reasonable such approximations.

Ref. [8] develops a fluid-structure interaction model for a wind turbine. The authors implement an iterative procedure to optimize the geometry of the blade through performance theories and then compare the results obtained with a standard blade profile. They conclude with the obtaining of greater torques for the turbine in the optimized model but, at the same time, with greater stresses and structural deformations.

The creation and genetic breeding of random individuals modifies its flow conditions and / or the geometry, searching to improve the aerodynamic performance of the individual. Refs. $[9,10]$ change the flow direction on the individuals. Refs. [11, 12, 13] modify surface geometry of the individuals. These experimentations can be conducted in wind tunnels and / or CFD. The disadvantage of these methods is the trial - and - error way to achieve the desired performance.

Table 2. Experimental setup / Initial conditions.

\begin{tabular}{|c|c|c|c|c|c|c|c|}
\hline$\Omega$ & $\Gamma$ & $\begin{array}{c}V_{\infty} \\
{[\mathrm{m} / \mathrm{s}]}\end{array}$ & $\begin{array}{c}P_{\text {ref }} \\
{[\mathrm{atm}]}\end{array}$ & $\begin{array}{c}w \\
{[\mathrm{~m}]}\end{array}$ & $\begin{array}{c}h \\
{[\mathrm{~m}]}\end{array}$ & $\begin{array}{c}a \\
{[\mathrm{~m}]}\end{array}$ & $\begin{array}{c}b \\
{[\mathrm{~m}]}\end{array}$ \\
\hline $\begin{array}{l}\text { air at } \\
25^{\circ} \mathrm{C}\end{array}$ & $\begin{array}{c}\text { body } \\
\text { boundary }\end{array}$ & 80 & 1 & 35 & 30 & 1.5 & 3 \\
\hline
\end{tabular}

Source: the authors.

Ref. [14] presents the fitting of parametric B-Spline curves to large sets of points originated in the cross section of an airfoil. The manuscript optimizes different curve parameters (stages, knot sequences, stage degree, control polygon, continuity, etc.) to obtain a reasonable curve fit with a minimum of computational effort (given the large point set). This manuscript does not seek to design or re-design the airfoil profile, as it takes already existing ones. Therefore, it does not make the connection between wing profile against hydro- or aero-dynamic flow conditions.

Ref. [15] implements CFD simulations for different radius of curvature of a tracheal carina. The manuscript performs the parameterization of the carina based on a simple bifurcation model and variates the radius of curvature. Although the methodology discusses relations between the radius of curvature and flow behaviour, it does not apply any optimization over the carina shape.

\subsection{Conclusions of the literature review}

Optimization methods need of an initial guess to be carried out. Creation of random individuals present a trial - and - error methodology. Experimental approaches concentrate on the variation of geometrical and/or flow conditions and do not seek optimal conditions. This work intends to evolve, gradually, an initial rectangular profile into a wing profile using Fluid Mechanics indicators. Our approach is a pragmatic strategy to drive the optimization. However, it is not general and it is not fully automated. Table 1 presents an overview of the literature review:

\section{Methodology}

\subsubsection{Computer Experimental Setup}

The experiment is carried out in the software ANSYS Academic Research Fluent, Release 17.2. The initial model consists in a $2 \mathrm{D}$ profile $(\Gamma)$ immersed in a fluid $(\Omega)$ moving at a certain velocity $\left(V_{\infty}\right)$ such that $\vec{V}(x=-w)=$ $V_{\infty} \hat{\mathbf{i}}+0 \hat{\mathbf{j}}$ as seen in Fig. $1 \Omega$ is bounded for parameters $w$ and $h . \Gamma$ is defined at the first stage by the parameter $a$ and $b$ in Table 2.

\section{Assumptions}

1. $\Omega$ is a Newtonian fluid region $\in R^{2}$ with constant density and viscosity. This is because the Mach number for $V_{\infty}$ is less than 0.3 being an incompressible flow [18].

2. $\Gamma$ rigid with no slip condition. Therefore, Velocity (V) in body boundary is 0 . 
3. Steady state flow (i.e. the derivative of the fluid properties with respect to time is equal to zero).

4. Transition Shear Stress Transport model (SST) for CFD solution. SST model is highly accurate in the predictions of flow separation. Captures eddies phenomena and reaches convergence.

Notice that, due to the finite element size and differential equation modeling, the phenomenon of eddies is not really modelled here. At this modeling level, we only make use of the fact that zero velocity boundaries in the interior of the fluid domain (i.e. not related to material walls) mark the existence of regions in which phenomena such as eddies occur. Our (admittedly draconian) approach is to deny such regions to the fluid by moving the wing profile to those limits. Since there is a zero velocity in such new profile boundaries, we do not violate continuity laws, and in coarse manner simply avoid the problematic eddy regions, without modeling them.

At this time, we are conscious of the fact that the finite element mesh used to model the flow must be optimized. Such an optimization includes both topological (i.e. interpolation degree, number of nodes, etc.) as well as geometrical (sensitive element size) aspects. We have used generic and possibly non - efficient mesh topology and geometry. Future endeavors shall include such considerations. Fig. 2 shows sizing and inflation methods used for the first stage of the process.

\subsection{Shape Evolution Process}

Todas Shape evolution process is carried out in a pragmatic and intentional way, evolving the shape from a rectangular profile into a wing profile adding or removing material Fig. 3 illustrates the evolution process.

1. Goal: To satisfy a lift force s.t. $F_{L} \geq 10000 \mathrm{~N}$ and to reduce drag force $F_{D}$ with respect to $F_{D_{0}}$. Eq. 1 and Eq. 2 show how the forces are computed with their discrete form [18].

2. Criteria: Reduction of pressure on the upper surface by increasing there the stream velocity in order to produce pressure difference (i.e. lift force). Reduction of drag by producing laminar flow (avoid streamlines divergence from $\Gamma$ ). Avoid zero velocity neighborhoods.

$$
\begin{aligned}
& F_{L}=\oint P d x \approx \sum P_{n}\left(\Delta x_{n}\right) \\
& F_{D}=\oint P d y \approx \sum P_{n}\left(\Delta y_{n}\right)
\end{aligned}
$$

\subsection{Fluid Mechanics Indicators}

The Fluid Mechanical indicators to conduct the shape evolution are three. Velocity scalar map, pressure scalar map and streamlines curvature. These indicators are analyzed in each stage of the evolution. Velocity- and pressure- scalar map are taken directly from the ANSYS postprocessor as a result of the solution of the Navier Stokes equations.

Curvature of the streamlines are obtained as follow. A function interrogates ANSYS database. Then, curvature is calculated from Eq. 3 as a discrete curve how it is indicated in [19].

$$
C_{i}=\frac{\left|t_{i}-t_{i+1}\right|}{\left|\left[\left(v_{i}+v_{i+1}\right) / 2\right]-\left[\left(v_{i-1}+v_{i}\right) / 2\right]\right|}
$$

Where $v_{i}$ is the i-th vertex of the streamline is, $t_{i}$ is the vector going from $v_{i}$ to $v_{i+1}$ and $C_{i}$ is the curvature at $v_{i}$. The calculation of $C_{i}$ in all the streamlines allows to draw the curvature scalar map.

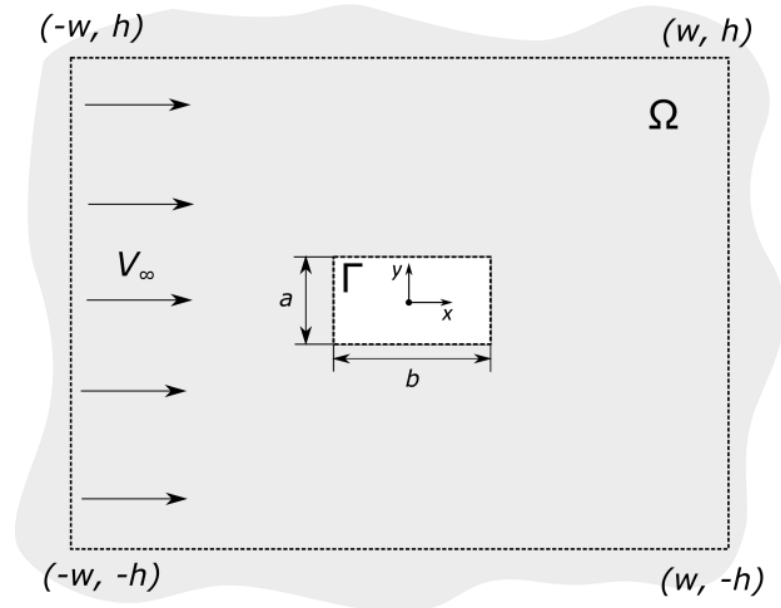

Figure 1. Diagram of the model at initial stage. Source: the authors.

\section{Results}

Four iterations were carried out, observing the fluid mechanics indicators (mentioned in section 3.3) for each stage of the process. The results are illustrated in this section. Figs. 4 and 5 show shape- and force- evolution respectively, as follows.

- $\quad$ Stage 1. Fig 4 (a), (b), (c) presents symmetry between the upper and lower surfaces, resulting in null lift. High pressure in front produces a drag significantly greater than lift. Streamlines 


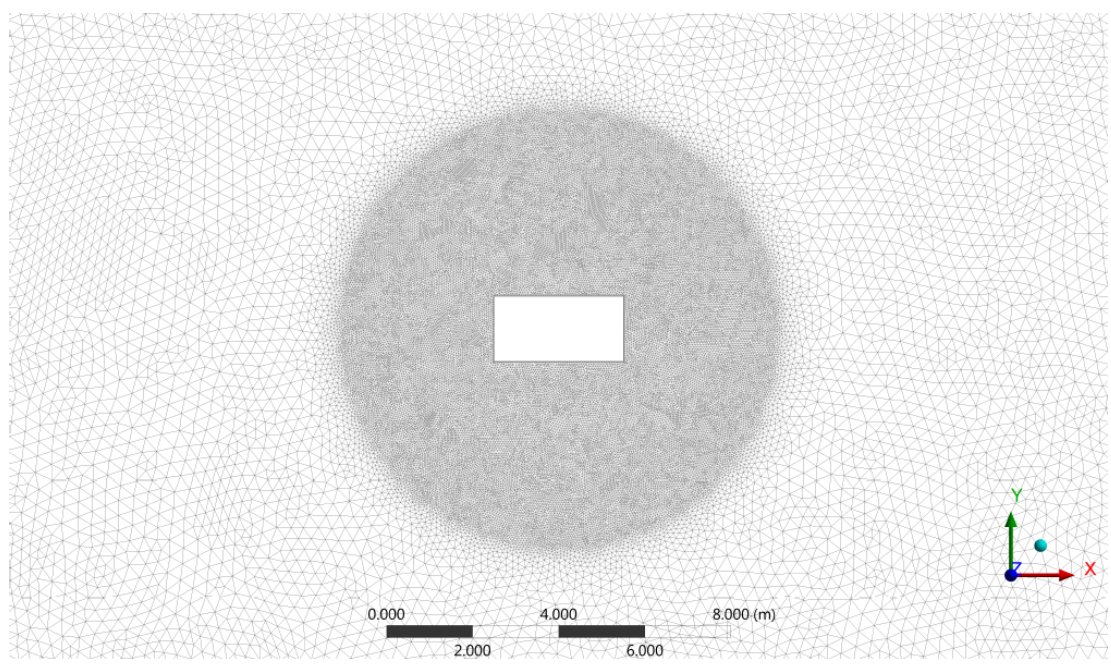

(a) Detail of sizing

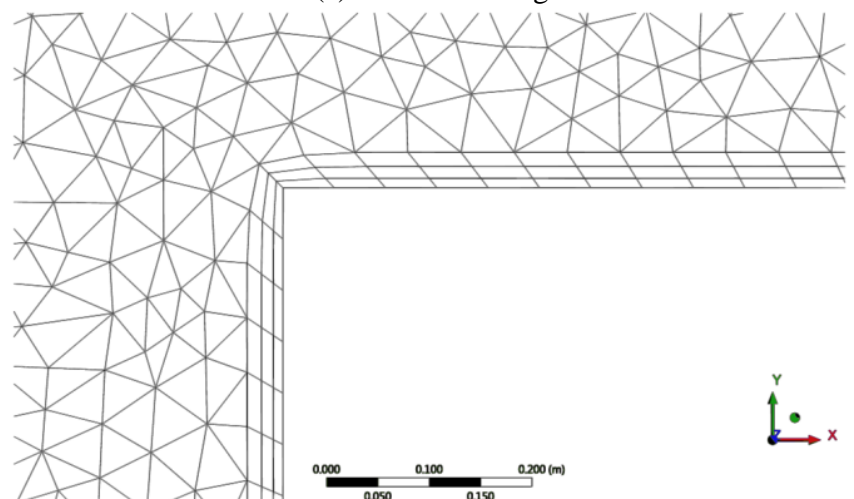

(b) Detail of inflation

Figure 2. Mesh for initial stage. Source: the authors.

diverging from the profile boundary suggest non-laminar flow (to be avoided). There are high curvature values in front and corners of $\Gamma_{0}$.

- $\quad$ Stage 2. Fig 4 (d), (e), (f). To reduce high pressure in front of $\Gamma$ and the high curvature, the corners are rounded. The stage presents a significantly reduction of drag and emergence of lift. Streamlines are tighter to the profile. Asymmetry appears.

- $\quad$ Stage 3. Fig 4 (g), (h), (i). Lift presents high increase with respect previous stages (see Fig.

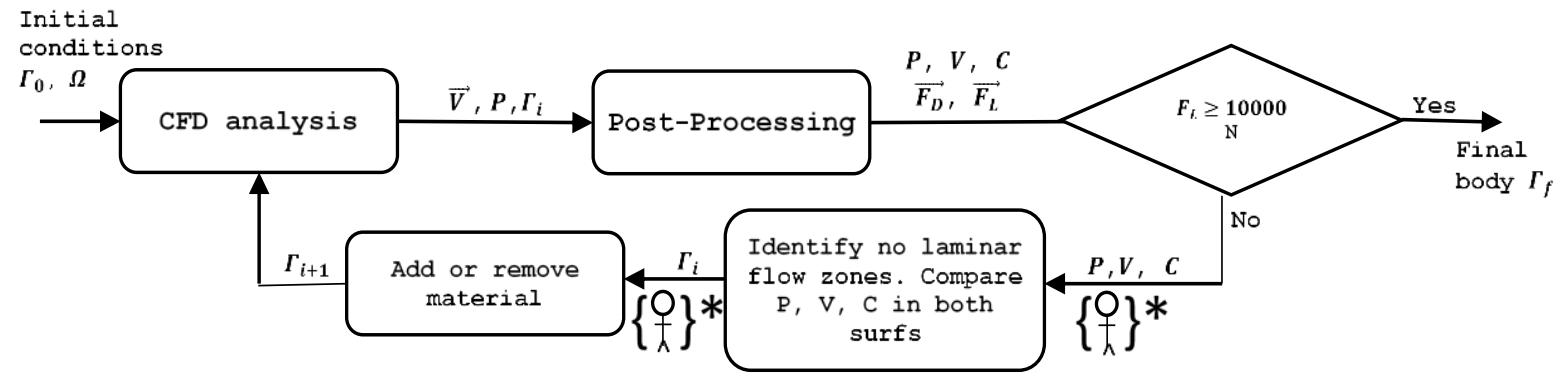

Figure 3. Evolution process diagram. *: Human iterative interaction. Source: the authors. 


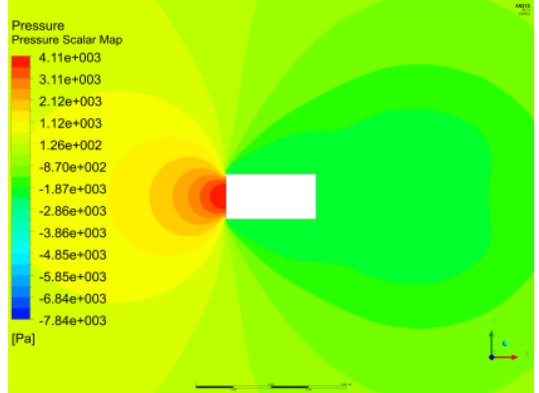

(a)

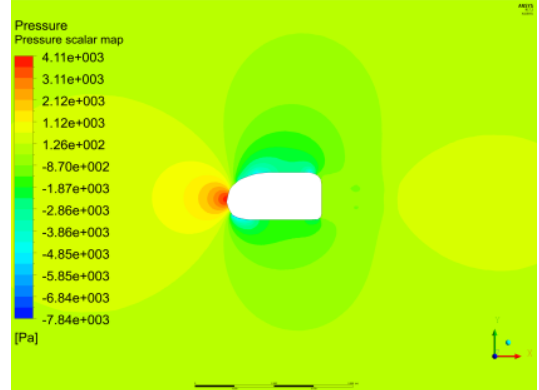

(d)

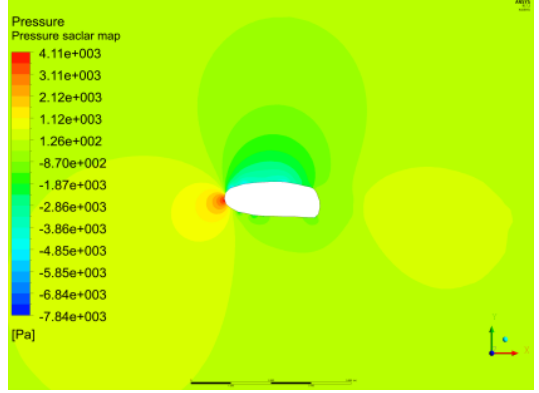

(g)

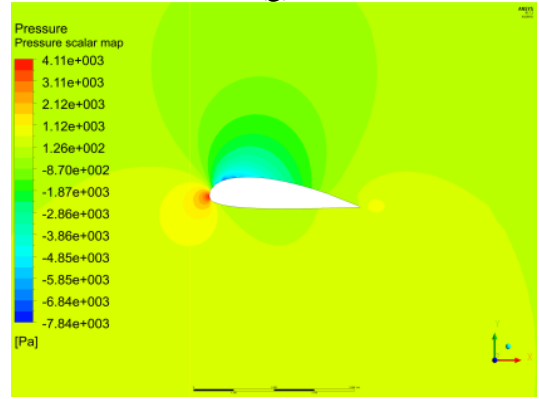

(j)

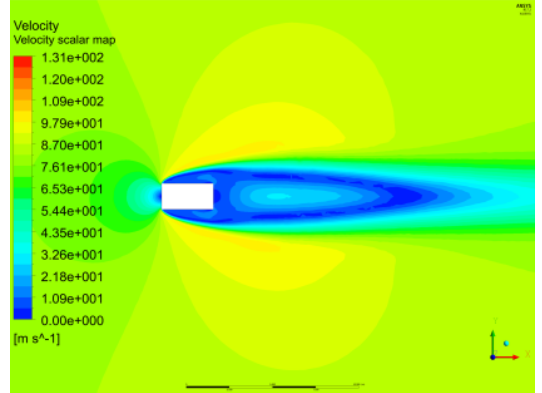

(b)

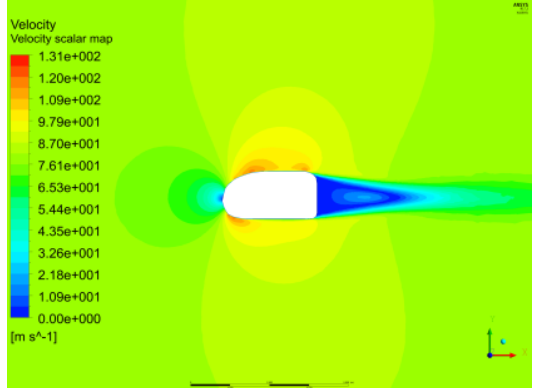

(e)

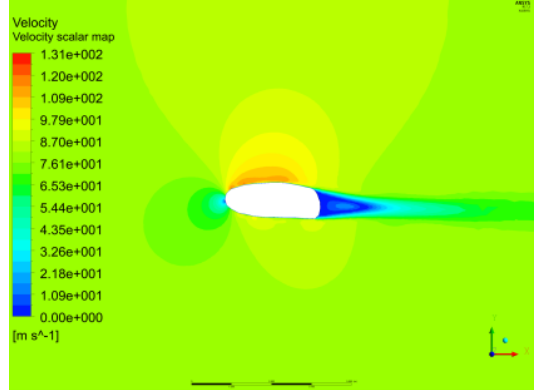

(h)

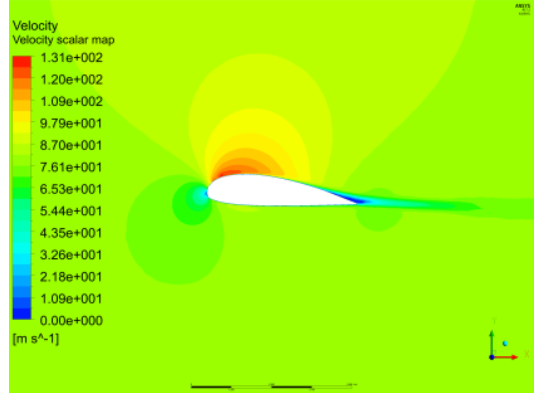

(k)

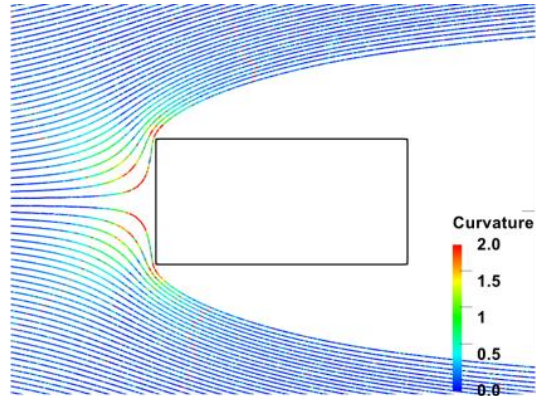

(c)

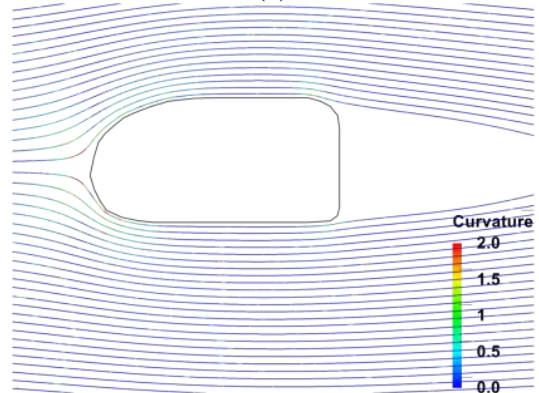

(f)

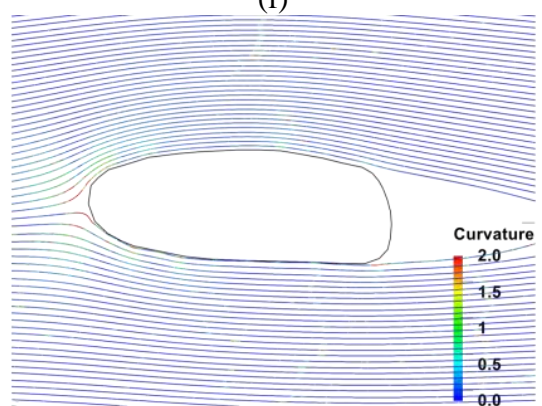

(i)

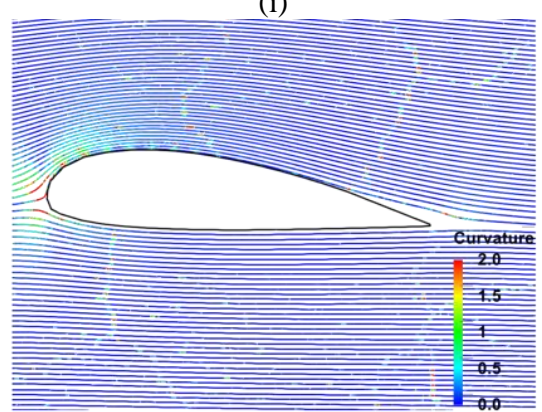

(1)

Figure 4. Evolution scalar maps of velocity, pressure and streamlines. Source: the authors.

5(b)). The back is rounded reducing the zero velocity neighborhoods.

- $\quad$ Stage 4. Fig 4 (j), (k), (l). The lift reaches 13000 $\mathrm{N}>10000 \mathrm{~N}$ (see Fig. 5 (b)). The zero velocity zones are filled by the object. The streamlines fit completely to the profile. Velocity at lower surface is largely equal to the flow velocity $V_{\infty}$.

\subsection{Algorithms Complexity}

Three algorithms are implemented for the stages analysis. To calculate the complexity of these algorithms the measure variable is the number of elements in the mesh। $N_{e}$. Being the number of elements in a horizontal line in $[-w, w]$ or vertical line in $[-h, h]$ is $O\left(\sqrt{N_{e}}\right)$. Table 3 shows a brief description of the algorithms. 


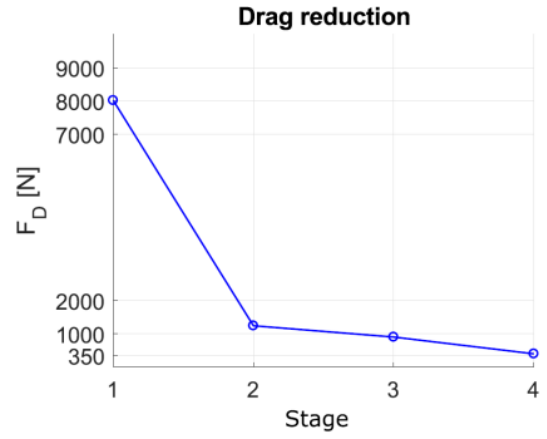

(a) Drag decrease

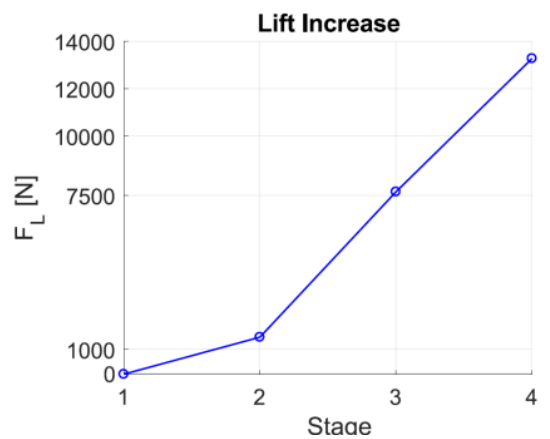

(b) Lift increase

Figure 5. Drag and Lift evolution. Source: the authors.

Table 3. Algorithms description and complexity.

\begin{tabular}{|l|l|c|}
\hline Algorithm & Description & Complex. \\
\hline $\begin{array}{l}\text { ANSYS } \\
\text { Database } \\
\text { interrogation }\end{array}$ & $\begin{array}{l}\text { This functions } \\
\text { interrogates ANSYS } \\
\text { data base to import } \\
\text { velocity, pressure and } \\
\text { streamlines } \\
\text { information. }\end{array}$ & $O\left(N_{e}\right)$ \\
\hline $\begin{array}{l}\text { Lift and } \\
\text { Drag } \\
\text { calculation }\end{array}$ & $\begin{array}{l}\text { Function that applies } \\
\text { Eqs. 1 and 2 to find the } \\
\text { forces acting on the } \\
\text { wing profile. }\end{array}$ & $O\left(N_{e}\right)$ \\
\hline $\begin{array}{l}\text { Curvature } \\
\text { calculation }\end{array}$ & $\begin{array}{l}\text { Function that applies } \\
\text { Eq. 3 to a streamline in } \\
\text { order to calculate the } \\
\text { curvature on its vertex. }\end{array}$ & $O\left(\sqrt{N_{e}}\right)$ \\
\hline
\end{tabular}

Source: the authors.

\section{Conclusions and Future Work}

Figs. 4 (b) and 5 (a) show that perpendicular surfaces to the flow increase drag by high pressure zone in front. Streamlines show the response of the corner rounding favoring both reduction of drag (Fig. 5 (a) shows higher reduction of drag) and laminar flow (see Fig. 4 (f)). Streamlines along the evolution validate the reduction of drag by making the flow more closed to laminar [16]. It occurs when there is not separation between streamlines and the profile. Production of lift seems favored by an asymmetric shape respect flow direction where the inclination is a determinant aspect.

Zero velocity combined with low pressure zones suggest presence of eddies and this zones can be filled by the object improving the aerodynamic behavior. In this sense, mathematical models based into reducing zero velocity and low pressure zones can be developed taking into account that there is no transfer of momentum at their boundary. Both, the experimental method presented, and a hypothetical mathematical model could be automated in a future work. This methodology can be applied for the development of devices and the understanding of fluid dynamics with submerged bodies.

\section{Glossary}

$\Omega \quad$ Rectangular orthogonal simulation domain $\in$ $R^{2}$ with center in $(0,0) . x \in[-w, w]$ and $y \in$ $[-h, h]$.

$\Gamma \quad$ Wing profile represented as a simple closed curve $\in R^{2}$ immersed in $\Omega$.

$V_{\infty} \quad$ Flow velocity at $x=-w$.

$V \quad$ Velocity magnitude at a point $\in \Omega$.

$P_{\text {ref }} \quad$ Magnitude of reference pressure.

$P \quad$ Pressure magnitude at a point $\in \Omega$.

$F_{L} \quad$ Lift force acting on $\Gamma$.

$F_{D} \quad$ Drag force acting on $\Gamma$.

$C$ Streamlines curvature.

$N_{e} \quad$ Number of mesh elements.

\section{References}

[1] A. Fathi and A. Shadaram, "Multi-level multiobjective multi-point optimization system for axial flow compressor 2d blade design," Arabian Journal for Science and Engineering, vol. 38, no. 2, pp. 351-364, 2013.

[2] P. Nørtoft and J. Gravesen, "Isogeometric shape optimization in fluid mechanics," Structural and Multidisciplinary Optimization, vol. 48, no. 5, pp. 909925, 2013.

[3] E. Immonen, " $2 d$ shape optimization under proximity constraints by cfd and response surface methodology," 
Applied Mathematical Modelling, vol. 41, pp. 508-529, 2017.

[4] K. Zhao, Z. Gao, J. Huang, and Q. Li, “Aerodynamic optimization of rotor airfoil based on multi-layer hierarchical constraint method," Chinese Journal of Aeronautics, vol. 29, no. 6, pp. 1541-1552, 2016.

[5] R. Mukesh, K. Lingadurai, and U. Selvakumar, "Airfoil shape optimization using non- traditional optimization technique and its validation," Journal of King Saud University - Engineering Sciences, vol. 26, no. 2, pp. 191-197, 2014.

[6] E. Gillebaart and R. De Breuker, "Low-fidelity 2d isogeometric aeroelastic analysis and optimization method with application to a morphing airfoil," Computer Methods in Applied Mechanics and Engineering, vol. 305, pp. 512-536, 2016.

[7] T. Zhao, Y. Zhang, H. Chen, Y. Chen, and M. Zhang, "Supercritical wing design based on airfoil optimization and $2.75 \mathrm{~d}$ transformation," Aerospace Science and Technology, vol. 56, pp. 168-182, 2016.

[8] Andres Espinosa-Moreno and Carlos Duque-Daza, "Efecto del radio de redondeo de la carina en el desarrollo del flujo a traves de un modelo sintetico de vias respiratorias," Rev. UIS Ing., vol.17, no. 2, pp. 215-222, 2018.

[9] S. Askari and M. Shojaeefard, "Shape optimization of the airfoil comprising a cross flow fan," Aircraft Engineering and Aerospace Technology, vol. 81, no. 5, pp. 407-415, 2009.

[10] L. Patruno, M. Ricci, S. de Miranda, and F. Ubertini, "Numerical simulation of a 5: 1 rectangular cylinder at non-null angles of attack," Journal of Wind Engineering and Industrial Aerodynamics, vol. 151, pp. 146-157, 2016.

[11] C. Park and S. Lee, "Effects of free-end corner shape on flow structure around a finite cylinder," Journal of Fluids and Structures, vol. 19, no. 2, pp. 141-158, 2004.

[12] S. Jain, V. D. Bhatt, and S. Mittal, "Shape optimization of corrugated airfoils," Computational Mechanics, vol. 56, no. 6, pp. 917-930, 2015.

[13] S.-H. Seo and C.-H. Hong, "Performance improvement of airfoils for wind blade with the groove," International Journal of Green Energy, vol. 13, no. 1, pp. 34-39, 2016.
[14] F. Pérez-Arribas and I. Castañeda-Sabadell, "Automatic modelling of airfoil data points," Aerospace Science and Technology, vol. 55, pp. 449-457, 2016.

[15] Kevin Molina, Daniel Ortega, Manuel Martinez, William Pinto-Hernandez, and Octavio Andres Gonzalez-Estrada "Modelado de la interaccion fluido estructura (fsi) para el diseno de una turbina eolica hawt", Rev. UIS Ing., vol. 17, no. 2, pp. 269-282, 2018. doi: 10.18273/revuin.v17n2-2018023

[16] D. SS, V. PMHW et al., "Design of fuselage shapes for natural laminar flow," NASA Langley Technical Report Server, Tech. Rep., 1986.

[17] Y. Ogawa and M. Kawahara, "Shape optimization of body located in incompressible viscous flow based on optimal control theory," International Journal of Computational Fluid Dynamics, vol. 17, no. 4, pp. 243251, 2003.

[18] Y. A. C, engel, J. M. Cimbala, V. C. Olguín, and S. F. Skarina, Mecánica de fluidos: fundamentos y aplicaciones. McGraw-Hill S ${ }^{\sim}$ ao Paulo, 2006, vol. 1.

[19] P. Manfredo, do Carmo. Differential geometry of curves and surfaces, 1st ed. Prentice Hall, 1976, chapter 1.

[20] B. Mohammadi and O. Pironneau, "Shape optimization in fluid mechanics," Annual Reviews of Fluid Mechanics, vol. 36, pp. 255-279, 2004. 